\section{Access to Armenia}

Soviet Journal of Contemporary Physics - Armenian Academy of Sciences. Soviet Editor G.M. Garibyan. Allerton, New York. 6/yr. North America \$430; elsewhere $\$ 465$.

THIS journal consists of fairly short (usually five or six pages) original papers, nearly all of them emanating from the various institutions in Erevan, the capital of the Armenian SSR. The scope is wide-ranging, covering theoretical and experimental work in many branches of physics.

In the five issues sent to me for review, the subjects covered include thin-film semiconductors, plasma physics, stimulated Raman scattering, hydrodynamics, $\mathrm{X}$-ray diffraction, liquid crystals, nonlinear optics, particle physics, semiconductor junctions, spin glasses and picosecond techniques. Many of the papers consist of calculations predicting the behaviour of rather specialized models, rather than discussions of general theories of physical phenomena. For light relief there is also the occasional eulogy on some eminent physicist who has broken through the octogenarian barrier.

The English translation is quite satisfactory. This is more than can be said for the general level of production. which even in a spirit of generosity cannot be

\section{H.M. Rosenberg}

said to be barely more than adequate. The print is double-spaced typescript from the pre-word-processor era, with paste-ups of formulae and expressions from the original journal, and the paper is a matt yellowish duplicating grade that most schools would be ashamed to use to inform parents about a forthcoming sports day. The reproduction of the figures from the original journal is just about legible and the few half-tone plates that there are appear as variegated splodges of grey on grey.

In the English translation the pagination starts afresh with page 1 for each individual issue, so that when these are bound into volumes there will be endless confusion. In the Russian original the pages run consecutively through the issues that make up a volume in the conventional manner. Allerton Press - surely you can do better than this?

Speed of publication does not appear to be at a premium in the Armenian SSR. Most of the contributions seem to have taken at least a year to get into (Russian) print and there is about a further year's delay for the translation - the journal can hardly be said to keep you up to date with recent developments. That criticism apart, there are some interesting papers to be studied. So although this is not a journal for a small specialized library, it must surely find a place in the stacks of central repositories.

H.M. Rosenberg is Reader in Physics at the Clarendon Laboratory, University of Oxford, Oxford OXI $3 P U, U K$.

\section{Living by numbers}

William A. Light

Soviet Journal of Numerical Analysis and Mathematical Modelling. Editor-in-chief G.I. Marchuk. VNU.6/yr. DM970, \$462.

As its title declares, this journal consists of English translations of selected Russian papers on numerical analysis and mathematical modelling. Numerical analysis is an active and diverse area in Soviet and Western mathematics, and no publication can provide truly comprehensive coverage of all topics or methods of approach to the subject. For example, there are some numerical analysts whose chief aim is the development of computer code for practical purposes, while others are much more interested in the mathematical foundations of the area and may know little about the associated computer codes.

The journal aims to publish papers which concentrate on the theoretical rather than the practical aspects. It is therefore inappropriate for someone who wants to find carefully described methods and/or computer code. Instead it will appeal to researchers who are already mathematicians, particularly those with a strong interest in the theoretical aspects of numerical analysis; although from its title the journal might be expected to be divided roughly equally between numerical analysis and mathematical modelling, the copies that I looked at were biased towards numerical analysis.

Within this subject area, the early issues have a strong leaning towards differential equations, and towards partial differential equations in particular. Only six issues had appeared at the time of writing this review, so it is a little early to identify trends. It must also be said that the numerical solution of partial differential equations is a thriving area, and perhaps it is predictable that there is a preponderance of papers on this topic.

The quality of the journal is, in my estimation, very high. The editor-in-chief and the members of the editorial board are all of considerable standing in the Soviet academic world, and their early selection of papers is excellent. This is no surprise; choosing from a large number of Soviet authors in such an active field, one would expect to see, in the main, a good standard of research methodology and

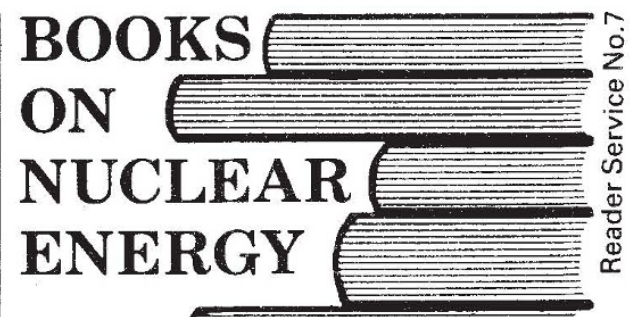

for the specialist for the public

For our free catalog call or write:

AMERICAN NUCLEAR SOCIDTY

555 N. Kensington Avenue

La Grange Park, Illinois 60525 312-352-6611 writing. There is, of course. a time lag between appearance of the papers in English and their original publication in Russian. but from a random survey this seems to be relatively bricf - about two years on average. Most of the papers also appear to come from preprints of the Department of Numerical Mathematics of the Soviet Academy of Sciences.

These days, for many research establishments one of the important considerations in subscribing to a journal is that of price and value for money. This journal is comparatively expensive. even though the costs of translation must be taken into account. The six issues of Vol. 2 cost approximately $£ 320$ at today's rate of exchange (the price of the journal is fixed ir: deutschmarks). Each issue contains four or five papers of average length 12 to 15 pages. The standards of printing and translation are both high. and each issue is a pleasure to read.

This journal certainly fills a gap in the world of numerical analysis, and many researchers will now be able to become more familiar with important Soviet developments in the field. But the cost of that familiarity will be much higher than that of many Western journals in the same area.

William A. Light is a Lecturer in the Department of Mathematics, University of Lancaster, Lancaster $L A I A Y L, U K$ 